\title{
REKOMENDASI PENERAPAN MANAJEMEN KARIR BERDASARKAN TALENTA PEGAWAI PT $X$
}

\author{
Mohammad Mizmara Alan Falihin \\ Minat Studi Manajemen Pemasaran dan Keuangan Pelayanan Kesehatan \\ Program Studi S2 Administrasi dan Kebijakan Kesehatan \\ Fakultas Kesehatan Masyarakat, Universitas Airlangga \\ Email: mizphi.fia@gmail.com
}

\begin{abstract}
Career management became a priority for improvement in X Company Employee surveys in 2014. Unfortunately, career planning has not been focused in human resource management. The study aimed to provide recommendations for employee planning and career development planning in the X Company. This descriptive research used cross sectional design. Data was taken through literature study, observation and document review. This study proves the importance of career management in the $X$ Company. Career management is one element in the preparation of talent pool. Through good career management, it will have a positive impact for both the company and the individual itself. X Company is expected to conduct a more in-depth study on the formulation and implementation of career planning and development that will be implemented in the $X$ Company and involves employees, human resource development, and organizations in the formulation and implementation.
\end{abstract}

Keywords: Human Resources Management, Career Management, Talent of Employee

\begin{abstract}
ABSTRAK
Manajemen karir menjadi priority for improvement pada survei pegawai PT X di tahun 2014. Sayangnya, perencanaan karir belum diperhatikan dalam manajemen sumber daya manusia. Penelitian bertujuan untuk memberikan rekomendasi penerapan perencanaan dan pengembangan karir pegawai di PT X. Penelitian deskriptif ini menggunakan desain cross sectional. Pengambilan data penelitian melalui studi literatur, observasi dan review dokumen. Penelitian ini membuktikan pentingnya pengelolaan karir di PT X. Manajemen karir merupakan salah satu unsur dalam penyusunan talent pool. Melalui pengelolaan karir yang baik, maka akan memberikan dampak positif baik bagi perusahaan ataupun individu itu sendiri. PT X diharapkan dapat melakukan studi lebih mendalam mengenai perumusan dan implementasi perencanaan dan pengembangan karir yang akan diterapkan di PT X dan melibatkan pegawai, bidang pengembangan sumber daya manusia, dan organisasi dalam perumusan dan penerapannya.
\end{abstract}

Kata kunci: Manajemen Sumber Daya Manusia, Manajemen Karir, Talenta Pegawai 


\section{PENDAHULUAN}

PT X telah menyelenggarakan program Jaminan Kesehatan Nasional (JKN) sejak 1 Januari 2014 (UU 24/2011, pasal 60 ayat 1). Selama dua tahun beroperasi, terjadi perkembangan organisasi yang signifikan. Berkembangnya organisasi tidak terlepas dari keinginan setiap individu yang berada di dalam organisasi, agar mampu mencapai tujuan jangka panjang organisasi.

Perkembangan PT X berasal dari struktur organisasi dan pertumbuhan karyawan. Perkembangan struktur organisasi dilakukan dari tingkat pusat (perumus kebijakan) sampai tingkat daerah (pelayanan operasional) dalam rangka memenuhi amanat undang-undang No 40 tahun 2004 dan No 24 tahun 2011. Seiring dengan perkembangan struktur organisasi dan pencapaian tujuan organisasi dalam memberikan kepuasan pelayanan kepada peserta, rekrutmen karyawan baru dilakukan.

Selama dua tahun, operasional PT X telah terjadi penambahan karyawan sebanyak dua kali lipat dari 4.000 karyawan menjadi hampir 8.000 karyawan. Organisasi memiliki kewajiban untuk memanfaatkan semaksimal mungkin kemampuan karyawan dan memberikan semua karyawan kesempatan untuk tumbuh dan menyadari potensi mereka serta mengembangkan karir. James W. Walker menyatakan bahwa organisasi butuh untuk menggerakkan individu melalui jalur karir untuk mengembangkan kemampuan yang diperlukan guna mengisi tingkat dan tipe pekerjaan manajemen yang ada dalam organisasi. Untuk itu manajemen karir atau pengelolaan karir pegawai yang meliputi tahapan kegiatan perencanaan karir, pengembangan dan konseling karir, serta pengambilan keputusan karir harus dilaksanakan oleh suatu perusahaan yang ingin berkinerja tinggi.

Sehubungan dengan hal tersebut, maka manajemen karir yang melibatkan semua pihak termasuk pegawai yang bersangkutan dengan unit tempat pegawai bekerja, dan organisasi secara keseluruhan perlu dikembangkan di PT X. Permasalahan yang diangkat pada penelitian ini adalah proses perencanaan karir di PT X. Perencanaan karir belum sepenuhnya dilaksanakan dalam pengelolaan sumber daya manusia PT $X$ yang selama dua tahun terakhir mengalami pertumbuhan yang signifikan. Selain itu manajemen karir juga menjadi priority for improvement pada hasil employe opinion survei PT X tahun 2014. Penelitian bertujuan untuk memberikan rekomendasi penerapan perencanaan dan pengembangan karir pegawai di PT X.

\section{METODE PENELITIAN}

Penelitian deskriptif ini menggunakan desain cross sectional. Pengambilan data penelitian melalui studi literatur, observasi dan review dokumen. Penelitian ini menganalisis PT X meliputi kondisi organisasi, talenta pegawai, human capital information system sebagai dasar dalam menyusun rekomendasi 
penerapan perencanaan dan pengembangan karir pegawai di PT X.

\section{HASIL DAN PEMBAHASAN}

\section{Kondisi Organisasi}

Rencana strategis PT X tahun 2014-2019 telah disusun, proses penyusunan menggunakan metode balanced socorecard dimana salah satu keunggulannya adalah dapat melihat secara komprehensif semua aspek organisasi. Strategi yang dikembangkan dalam metode balanced scorecard tersebut disebut peta strategi. Berdasarkan peta strategi PT X perspektif finansial dan perspektif stakeholder menjadi tujuan dari organisasi.

Untuk memastikan tercapainya tujuan organisasi tersebut harus didukung oleh perspektif proses bisnis internal yang kuat sebagai proses inti dalam operasional perusahaan yang terdiri dari risk pooling, revenue collection dan purchasing. Untuk memastikan keberhasilan pencapaian proses pada perspektif bisnis operasional maka harus didukung oleh perspektif pembelajaran dan pertumbuhan yang baik. Dimana dalam hal ini perspektif pembelajaran dan pertumbuhan merupakan penerjemahan dari sasaran organisasi berupa Teknologi informasi yang handal, pengelolaan sumber daya manusia yang unggul dan kapabilitas organisasi yang dipercaya.

Rencana strategis organisasi tersebut selanjutnya lebih spesifik diterjemahkan kedalam level fungsi, dimana terdapat 25 fungsi yang merupakan penterjemahan dari Undangundang No 40 Tahun 2004 dan UU No.24 Tahun 2011. Salah satu dari fungsi tersebut dan yang khusus merepresentasikan dari sasaran organisasi pengelolaan sumber daya manusia yang unggul adalah fungsi manajemen sumber daya manusia.

Sebagaimana halnya peta strategi organisasi maka setiap fungsi turunannya tersebut juga telah disusunkan peta strateginya. Tujuan utama dari fungsi sumber daya manusia ini adalah tercapainya pengelolaan sumber daya manusia yang kompeten secara efektif (perspektif stakeholder) dan pengelolaan anggaran yang efektif dan efisien (perspektif finansial). Untuk memastikan tujuan utama fungsi manajemen sumber daya manusia tersebut tercapai maka harus didukung oleh perspektif proses bisnis internal yang menjadi inti proses manajemen sumber daya manusia merupakan tahapan proses manajemen sumber daya manusia.

\section{Talenta Pegawai}

Fokus pada pengelolaan talenta (talent management) bahwa terdapat unsur-unsur penting dalam pengelolaan talenta tersebut yang salah satunya adalah career management.

PT $X$ telah menerapkan sistem pengelolaan talenta berbasis kompetensi, sebagaimana diatur dalam Peraturan Direksi PT X nomor 97 tahun 2014 tentang Pedoman Manejemen Talenta. Dimana output dari 
pengelolaan talenta tersebut adalah berupa talent pool pegawai yang dipetakan berdasarkan kompetensi dan kinerja individu yang selanjutnya dipetakan kedalam diagram talenta sebagai berikut:

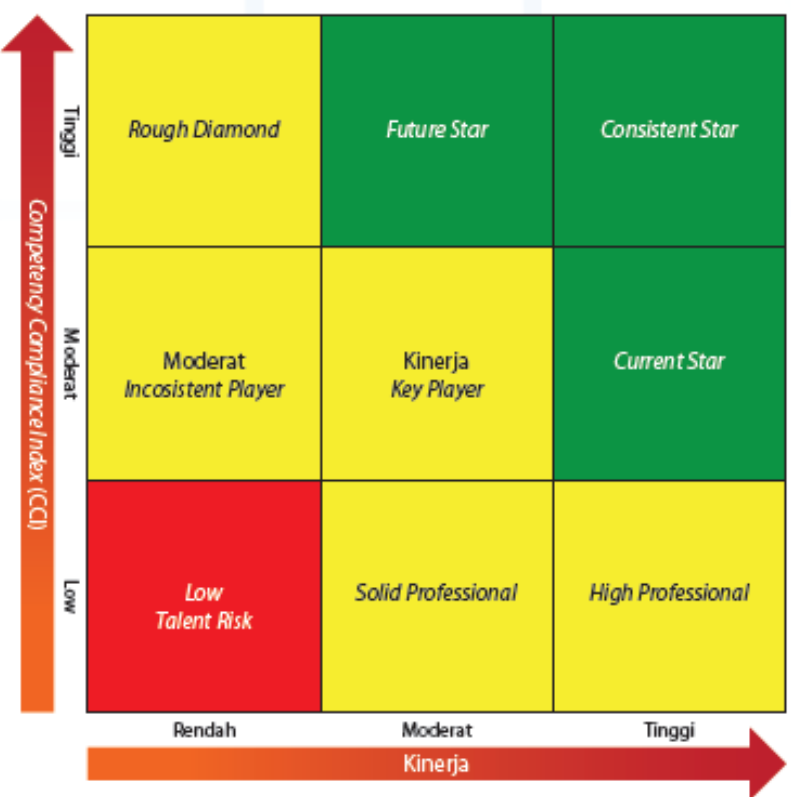

Gambar 1. Diagram Talenta PT X

Setelah setiap pegawai menempati posisinya masing-masing pada diagram talenta tersebut kemudian khusus untuk pegawai yang berada pada kelompok diagram berwarna hijau yaitu future star, curent star dan consisten star akan masuk kedalam talent pool pegawai diprioritaskan untuk mengikuti tahap assesment sebagai persyaratan promosi jabatan.

Dalam proses penilaian kompetensi dan kinerja pegawai PT X tersebut mengacu pada pengelolaan human capital, yaitu menganggap pegawai sebagai aset, bukan sumber daya. Pengelolaan pegawai tersebut dilaksankan secara terbuka melalui aplikasi dan dapat diakses dimana saja oleh pegawai. Pada aplikasi tersebut berisi informasi mengenai data pribadi pegawai, data pekerjaan pegawai, data model kompetensi dan capaian kompetensi pegawai, data posisi pegawai pada diagram talenta dan sebagainya.

\section{Human Capital Information System}

Penggunaan sistem pegawai berbasis kompetensi tersebut sebagaimana diatur dalam Peraturan Direksi PT X nomor 97 tahun 2014 tentang Pedoman SMKPBK. Pada SMKPBK, pegawai dinilai dari lima komponen, yakni:

1. Hasil kerja. Komponen hasil diukur berdasarkan tanggung jawab utama dan key performance indicator (KPI) pada setiap tanggung jawab pemangku jabatan dan dinilai oleh atasan langsung.

2. Kompetensi. Komponen Kompetensi yang diukur meliputi kompetensi dasar, kompetensi perilaku, dan kompetensi teknis yang dipilih oleh pegawai untuk dikembangkan pada periode tertentu dan dinilai secara multirater (360 derajat).

3. Komitmen. Komponen komitmen diukur melalui penilaian kesesuaian perilaku pegawai dengan key behaviour (perilaku yang diharapkan) yang dijabarkan pada tata nilai organisasi dan dinilai secara multirater (360 derajat).

4. Tugas Tambahan. Komponen tugas tambahan merupakan kegiatan diluar tanggung jawab utama pemangku jabatan yanng berasal dari atasan atau pihak lain, dengan memenuhi kriterian tertentu. 
Komponen ini tidak selalu ada dalam SMKPBK individu.

5. Kejadian Kritis. Komponen kejadian kritis merupakan pencatatan atas perilaku tertentu yang ditunjukkan oleh pegawai pada suatu waktu tertentu yang dianggap menonjol atau diluar kewajaran yang memberikan dampak positif/negatif kepada unit kerja/organisasi

\section{Usulan Perencanaan dan Pengembangan}

\section{Karir}

Berdasarkan kondisi PT X sebagaimana diuraikan diatas terdapat hal-hal yang perlu dilakukan perbaikan guna menjaga tercapainya tujuan fungsi manajemen sumber daya manusia yaitu pengelolaan sumber daya manusia yang kompeten secara efektif. Hal yang akan diulas pada pembahasan career management, dimana proses manajemen karir yang seharusnya menjadi salah satu input dalam proses talent pool belum dilakukan. Pembentukan talent pool masih berdasarkan komitmen, kompetensi dan kinerja.

Selain itu berdasarkan hasil employee opinion survey pegawai PT X tahun 2014 menunjukkan bahwa indeksi opini pegawai dimensi manajemen karir jauh di bawah total indeks opini pegawai secara keseluruhan, dimana untuk dimensi manajemen karir mendapatkan indeks sebesar $60,5 \%$ sedangkan secara keseluruhan dimensi mendapatkan indeks sebesar 72,54\%. Berdasarkan hasil survey tersebut, variabel pada dimensi karir menjadi area priority for improvement.

Tabel 1. Usulan Pengembangan Karir

\begin{tabular}{|c|c|c|c|c|c|c|}
\hline No & $\begin{array}{c}\text { Komponen } \\
\text { Manajemen Karier }\end{array}$ & & Normatif & $\begin{array}{c}\text { Yang dilaksanakan di BPJS } \\
\text { Kesehatan }\end{array}$ & Kelebihan / kelemahan & Perbaikan \\
\hline 1 & $\begin{array}{l}\text { Manajemen Karir } \\
\text { Individu }\end{array}$ & & $\begin{array}{l}\text { Pengelolaan pengembangan skill } \\
\text { dan wawasan dari setiap } \\
\text { karyawan }\end{array}$ & $\begin{array}{l}\text { Sistem penilaian kinerja berbasis } \\
\text { kompetensi dengan komponen } \\
\text { penilaian adalah hasil kerja, } \\
\text { kompetensi dan komitmen. }\end{array}$ & $\begin{array}{l}\text { Kelebihan : pengelolaan sudah } \\
\text { obyektif dan sudah dinilai secara } \\
\text { multirater } \\
\text { Kekurangan: pengembangan } \\
\text { kompetensi untuk pegawai yang sudah } \\
\text { sesuai model kompetensi kurang } \\
\text { terarah. }\end{array}$ & $\begin{array}{l}\text { Tambahan informasi model } \\
\text { kompetensi jabatan yang } \\
\text { menjadi jalur karirnya }\end{array}$ \\
\hline 2 & $\begin{array}{l}\text { Manajemen Karir } \\
\text { Organisasi }\end{array}$ & & $\begin{array}{l}\text { Proses penyusunan jalur karier } \\
\text { dari masing-masing karyawan } \\
\text { berdasarkan posisinya. }\end{array}$ & Belum ada & $\begin{array}{l}\text { Karyawan tidak mengetahui tujuan } \\
\text { karirnya serta hierarki posisi dalam } \\
\text { struktur organisasi perusahaan }\end{array}$ & $\begin{array}{l}\text { Adanya jalur karir setiap } \\
\text { karyawan. }\end{array}$ \\
\hline \multirow[t]{3}{*}{3} & Perencanaan Karier & a & Pendidikan karier & $\begin{array}{l}\text { Sudah ada pada sebagian } \\
\text { pegawai }\end{array}$ & $\begin{array}{l}\text { Kelemahan: Tidak seluruh pegawai } \\
\text { dapat merencanakan kariernya }\end{array}$ & $\begin{array}{l}\text { Adanya pendidikan karir pada } \\
\text { saat diklat dasar }\end{array}$ \\
\hline & & $\mathrm{b}$ & Penyediaan Informasi & $\begin{array}{l}\text { Sudah terdapat data informasi } \\
\text { pegawai pada aplikasi HCIS }\end{array}$ & $\begin{array}{l}\text { Kelemahan: Belum terdapat informasi } \\
\text { persyaratan jabatan yang ada dalam } \\
\text { jalur karirnya, seperti job family. }\end{array}$ & $\begin{array}{l}\text { Agar ditambahkan informasi } \\
\text { persyaratan jabatan dalam jalur } \\
\text { kariernya, atau job family atau } \\
\text { alternative jalur karier }\end{array}$ \\
\hline & & $\mathrm{c}$ & Career Counselor & $\begin{array}{l}\text { Coaching dan mentoring pada } \\
\text { saat pembinaan kinerja dalam } \\
\text { rangka pencapaian kinerja }\end{array}$ & $\begin{array}{l}\text { Kelemahan: tidak ada pembahasan } \\
\text { spesifik mengenai perencanaan karier }\end{array}$ & $\begin{array}{l}\text { Adanya career counselor yang } \\
\text { jelas. }\end{array}$ \\
\hline 4 & Jalur Karir & & Sistem dan metode Jalur Karir & $\begin{array}{l}\text { Pola penempatan pada pegawai } \\
\text { promosi berdasarkan klasifikasi } \\
\text { organisasi }\end{array}$ & $\begin{array}{l}\text { Kelemahan: Pola penempatan belum } \\
\text { dïnformasikan ke pegawai dan kurang } \\
\text { konsisten penerapannya }\end{array}$ & $\begin{array}{l}\text { sistem dan metode jalur karir } \\
\text { menggunakan kombinasi sesuai } \\
\text { jabatan masing-masing dan } \\
\text { dïnformasikan kepada pegawai }\end{array}$ \\
\hline 5 & Tujuan Karier & & $\begin{array}{l}\text { Tanda untuk menentukan arah } \\
\text { karier yang harus ditempuh } \\
\text { seseorang dan selaras dengan } \\
\text { keinginan organisasi }\end{array}$ & $\begin{array}{l}\text { Berdasarkan kepentingan } \\
\text { organisasi }\end{array}$ & $\begin{array}{l}\text { Kelemahan: Ketidakpuasan pegawai } \\
\text { meningkat karena belum jelasnya } \\
\text { tujuan karier organisasi dan individu }\end{array}$ & $\begin{array}{l}\text { Adanya career counselor yang } \\
\text { jelas. }\end{array}$ \\
\hline
\end{tabular}




\begin{tabular}{|c|c|c|c|c|c|c|}
\hline No & $\begin{array}{c}\text { Komponen } \\
\text { Manajemen Karier }\end{array}$ & & Normatif & $\begin{array}{c}\text { Yang dilaksanakan di BPJS } \\
\text { Kesehatan }\end{array}$ & Kelebihan / kelemahan & Perbaikan \\
\hline \multirow[t]{3}{*}{6} & Pengembangan Karier & $\mathrm{a}$ & Model pengembangan karir & Belum jelas & $\begin{array}{l}\text { Kelemahan: pegawai tidak mengetahui } \\
\text { model mana yang dipakai dan pada } \\
\text { jabatan mana }\end{array}$ & $\begin{array}{l}\text { Disusun model pengembangan } \\
\text { karir yang baku }\end{array}$ \\
\hline & & $\mathrm{b}$ & $\begin{array}{l}\text { Komponen sistem } \\
\text { pengembangan karier }\end{array}$ & Belum ada & $\begin{array}{l}\text { Kelemahan : tidak dapat membantu } \\
\text { menentukan jalur karir }\end{array}$ & $\begin{array}{l}\text { Penerapan komponen sistem } \\
\text { pengembangan karier }\end{array}$ \\
\hline & & $\mathrm{c}$ & $\begin{array}{l}\text { Penyusunan program } \\
\text { pengembangan karier }\end{array}$ & Belum ada & $\begin{array}{l}\text { Kelemahan : tidak dapat membantu } \\
\text { menentukan jalur karir }\end{array}$ & $\begin{array}{l}\text { Penerapan career need } \\
\text { assessment, career } \\
\text { opportunities dan need- } \\
\text { opprtunities alignment }\end{array}$ \\
\hline 7 & Feedback Karir & & $\begin{array}{l}\text { Memperbaiki diri sendiri dan } \\
\text { meningkatkan sasaran karier }\end{array}$ & $\begin{array}{l}\text { Coaching dan mentoring pada } \\
\text { saat pembinaan kinerja dalam } \\
\text { rangka pencapaian kinerja }\end{array}$ & $\begin{array}{l}\text { Kelemahan: tidak ada pembahasan } \\
\text { spesifik mengenai evaluasi karier }\end{array}$ & $\begin{array}{l}\text { Adanya career counselor yang } \\
\text { jelas. }\end{array}$ \\
\hline
\end{tabular}

\section{SIMPULAN DAN SARAN}

\section{Simpulan}

Manajemen karir merupakan salah satu unsur dalam penyusunan talent pool. Untuk itu perlu dikembangkan pengelolaan karir di PT X. Dengan pengelolaan karir yang baik akan memberikan dampak positif baik bagi perusahaan ataupun individu itu sendiri.

\section{Saran}

Diharapkan PT X dapat melakukan studi lebih mendalam mengenai perumusan dan implementasi perencanaan dan pengembangan karir yang akan diterapkan di PT X dan melibatkan pegawai, bidang pengembangan sumber daya manusia, dan organisasi dalam perumusan dan penerapannya.

\section{REFERENSI}

1. Amstrong, M., A Hand Book of Human Resource Management Practice. 10th ed. Philadelphia: Kogan Page. 2006.

2. Bambang, W., Manajemen Sumber Daya Manusia. Bandung: Sulita. 2002.
3. Fred, L.O. \& Peggy, G.H. Helping Employees Manage Careers. In Gaol, C.J.L. Human Capital : Manajemen Sumber Daya Manusia. Jakarta: Kompas Gramedia. p.252. 2014.

4. Gaol, C.J.L. Human Capital: Sumber Daya Manusia (Konsep, Teori dan Pengembangan dalam konteks organisasi publik dan bisnis). Jakarta: Kompas Gramedia. 2014.

5. Gibson, Ivanicevich \& Donnely. Organisasi: Perilaku, Struktur dan Proses. Jakarta: Erlangga. 1995.

6. Greenhaus \& Jeffrey, H. Career Management. In Irianto, J. Tema-tema Pokok Manajemen Sumber Daya Manusia. Surabaya: Insan Cendikia. 1987.

7. Gutteride, T.G. "Commentary : A Comparison of Perspective", Career in Organizational. pp.39-41. 1976.

8. Irianto, J. Tema-tema Pokok Manajemen Sumber Daya Manusia. Surabaya: Insan Cendikia. 2001.

9. Simamora, H. Manajemen Sumber Daya Manusia. Yogyakarta: STIE YPKN. 2001.

10. Utomo, H.J.N. \& Sugiarto, M. Manajemen Sumber Daya Manusia. Yogyakarta: Ardana Media. 2007. 